- Fábio Geraldo Curtis

- Robson Furlan

Yara M. M. Castiglia

\section{Bloqueio peribulbar para enucleação de globo ocular}

\author{
CET-SBA, Departamento de Anestesiologia da Faculdade \\ de Medicina da Universidade Estadual Paulista, Botucatu, São Paulo
}

INTRDDUCॄÃa

As complicações oftalmológicas freqüentemente são tratadas cirurgicamente sob anestesia geral. Apresentamos um caso de endoftalmite crônica por doença degenerativa corneana de Fuchs tratada cirurgicamente sob bloqueio peribulbar.

\section{RELATI DO CASL}

Paciente do sexo feminino, 70 anos, 40 kg, P2 (antigo ASA II), hipertensa controlada com uso de captopril e hidroclorotiazida, submetida à cirurgia para enucleação de globo ocular devido à endoftalmite crônica por úlcera de córnea. Apresentava-se em REG, com dor intensa no olho $(\mathrm{EVA}=9)$, taquicárdica $(\mathrm{FC}=130 \mathrm{bpm})$, hipertensa $(\mathrm{PA}=162 / 100 \mathrm{mmHg})$ e com leucocitose. Na sala de cirurgia foi monitorizada com cardioscópio (DII), pressão arterial não-invasiva e oxímetro de pulso. Oferecidos $2 \mathrm{l} / \mathrm{min}$ de $\mathrm{O}_{2}$ via cateter nasal, realizadas a punção venosa e a administração de $3 \mathrm{mg}$ de midazolam e $15 \mathrm{mcg}$ de fentanil, seguida de infusão contínua de propofol para sedação. O bloqueio peribulbar foi realizado com $8 \mathrm{ml}$ de ropivacaína $1 \%$ com clonidina $1 \mathrm{mcg} / \mathrm{kg}$, em duas punções: ínfero-lateral (5 ml) 10 minutos depois, para obter-se redução da pressão intra-ocular (PIO) e difusão do anestésico súpero-medial $(3 \mathrm{ml})$. Após $10 \mathrm{~min}$ da segunda punção, o olho estava imóvel e iniciou-se a cirurgia, que durou 150 minutos. Ao final da intervenção, a paciente apresentava-se consciente, $\mathrm{FC}=62 \mathrm{bpm}$,

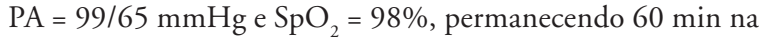
sala de recuperação pós-anestésica. Foram prescritos antibiótico e analgésicos no pós-operatório. A paciente não solicitou analgésicos no pós-operatório e apresentava-se ainda sem dor $(E V A=1)$ após 24 horas da cirurgia.

DISCUSSÃa

A realização do bloqueio peribulbar associada à sedação com propofol é opção segura e de qualidade, mesmo diante de complicações oftalmológicas.

REFERÊNCIAS

. Scott lU, et al. Local anesthesia with intravenous sedation for surgical repair of selected open globe injuries. Am J Ophthalmol. 2002;134:707-11.

2. Kmnar CM, et al. Orbital regional anaesthesia. In: Kumar CM, editor. Ophthalmic anaesthesia. 1st ed. Ireland: Swets \& Zeitlinger; 2002.p.61-88.

Endereço para correspondência:

Fábio Geraldo Curtis

Distrito de Rubião Júnior, Caixa Postal 530

Botucatu (SP) - CEP 18618-970

Fone: (+55 17) 222-2355/9608-2838

E-mail: fabio.curtis@uol.com.br 